Portland State University

PDXScholar

Physics Faculty Publications and Presentations

Physics

$4-12-2010$

\title{
Remote Plasma Assisted Growth of Graphene Films
}

Gopichand Nandamuri

Portland State University

Sergei Rouvimov

Portland State University

Raj Solanki

Portland State University

Follow this and additional works at: https://pdxscholar.library.pdx.edu/phy_fac

Part of the Physics Commons

Let us know how access to this document benefits you.

\section{Citation Details}

Nandamuri, G., Roumimov, S., \& Solanki, R. (2010). Remote plasma assisted growth of graphene films. Applied Physics Letters, 96(15), 154101

This Article is brought to you for free and open access. It has been accepted for inclusion in Physics Faculty Publications and Presentations by an authorized administrator of PDXScholar. Please contact us if we can make this document more accessible: pdxscholar@pdx.edu. 


\title{
Remote plasma assisted growth of graphene films
}

\author{
Gopichand Nandamuri, ${ }^{\text {a) }}$ Sergei Roumimov, and Raj Solanki \\ Department of Physics, Portland State University, Portland, Oregon 97207, USA
}

(Received 6 March 2010; accepted 22 March 2010; published online 13 April 2010)

\begin{abstract}
Single and multiple layers of graphene films were grown on (111) oriented single crystals of nickel and polycrystalline nickel films using remote plasma assisted chemical vapor deposition. Remote plasma was employed to eliminate the effect of the plasma electrical field on the orientation of the grown graphene films, as well as to reduce the growth temperature compared to conventional chemical vapor deposition. The electrical and optical properties, including high resolution transmission electron microscopy of these films, suggest that this approach is both versatile and scalable for potential large area optoelectronic applications. (c) 2010 American Institute of Physics. [doi:10.1063/1.3387812]
\end{abstract}

The unique electrical properties of graphene, in particular, ballistic transport and tunable transport properties have opened up exciting possibilities for this material as a replacement for silicon. ${ }^{1,2}$ Graphene has an unusually simple structure, consisting of hexagonal arrangement of carbon atoms in a single layer, and is mechanically and chemically stable. The most common method of producing single layers of this material has been via mechanical exfoliation of highly oriented pyrolytic graphite, however the sample dimensions are limited typically to tens of microns. ${ }^{3}$ For practical applications, large area graphene films on insulating substrates are required, especially for mass production of devices. To address this shortcoming, several techniques have been explored, including chemical vapor deposition (CVD) on transition metals, ${ }^{4-6}$ reduction of oxidized graphite films, ${ }^{7}$ and graphitization under high vacuum of $\mathrm{SiC}$ wafers. ${ }^{8}$ We consider below a chemical route for deposition of graphene on large areas with the goal of reducing the deposition temperature using an rf plasma.

We describe below remote plasma assisted CVD (RPCVD) of graphene films from methane and hydrogen as source gases. Although various transition metal substrates were examined, the discussion here will be limited to $\mathrm{Ni}$, which has a lattice mismatch of $1.1 \%$ and whose surface chemistry has been well investigated. ${ }^{9-11}$ During the deposition process, it is believed that decomposition of the carbon bearing sources produces carbon atoms which then dissolve into these metals as interstitials forming solid solutions. On cooling, the segregation of the carbon atoms leads to formation of the graphene layer(s). ${ }^{12}$ Transformation of the amorphous phase carbon to its inherently more stable crystalline counterpart generally requires a thermally assisted kinetic process involving nucleation and growth. However, it is well known that the crystallization temperatures can be significantly reduced in the presence of some transition metals due to their catalytic nature that assists in the transformation. ${ }^{13}$

The substrates in this investigation consisted of thin $(200$ and $300 \mathrm{~nm}$ thick) Ni films e-beam evaporated onto $100 \mathrm{~nm}$ thick $\mathrm{SiO}_{2}$ coated $\mathrm{Si}$ wafers, one micron thick $\mathrm{Ni}$ foils, and (111) oriented single crystal Ni. The deposited Ni films were first annealed at around $1000 \mathrm{C}$ in Ar to convert the amorphous films to polycrystalline phase, otherwise there was no

${ }^{a)}$ Electronic mail: nandamur@pdx.edu. graphene growth. With Ni films thinner than $200 \mathrm{~nm}$, the annealing step resulted into agglomeration of the metal film into particulates, resulting in discontinuous layers. Examination of the annealing step showed polycrystalline grains in the $300 \mathrm{~nm}$ thick layers, ranging in size from less than a micron to around $20 \mu \mathrm{m}$, determined with a scanning electron microscope. The size of graphene domains was consistent with these dimensions of the flat grain surfaces, strongly suggesting epitaxial growth on the microcrystallites. Substrate samples consisted of cleaved wafer pieces or strips of 1 micron thick $\mathrm{Ni}$ foil that varied in sized from $2 \times 5$ to 3 $\times 5 \mathrm{~cm}^{2}$, and $\mathrm{Ni}$ single crystals with about $2 \times 2 \mathrm{~mm}^{2}$ polished surfaces. All these substrates were precleaned by sonication in acetone and isopropyl alcohol before loaded into the reactor. The growth reactor consisted of a horizontal oven with a quartz tube. The substrates were inserted at one end of this reactor tube and the other end of the reactor was connected to a vacuum system that was pumped down to base pressure of $1 \mathrm{mTorr}(0.0013 \mathrm{~Pa})$ with a roughing pump and a roots blower. The quartz tube has a diameter of $3 \mathrm{~cm}$ and a length of $60 \mathrm{~cm}$. The gases were introduced into the reactor from two side arms. One of the side arms (diameter of $1 \mathrm{~cm}$ ) had a copper rf coil around it to induce a plasma $25 \mathrm{~cm}$ from the substrate. A Raman spectrometer operating at a wavelength of $532 \mathrm{~nm}$ was employed to analyze the deposited films.

Plasma assisted growth of graphene has been reported where the substrates were placed within the plasma reactors. ${ }^{14,15}$ In this configuration, the substrate is usually placed on top of one of the two electrodes used to generate the plasma, hence the substrate is immersed in the plasma. The electrodes will be surrounded with a sheath that will have a relatively high electric field and will be oriented perpendicular to their surfaces. ${ }^{16}$ Since the substrate sits on one of these electrodes, the sheath will also cover it. It is this field that tends to orient the growth of a graphene film perpendicular to the substrate surface, parallel to the electric field. Hence, the graphene nanosheets grown are in form of flakes. ${ }^{14,15}$ This technique is also used to grow carbon nanotubes aligned perpendicular to the surface. ${ }^{17}$ To eliminate this orientation dependence, an upstream remote plasma was utilized to produce planar graphene films with respect to the substrates. With the remote plasma configuration, graphene films were produced on $\mathrm{Ni}$ substrates with methane and hy- 


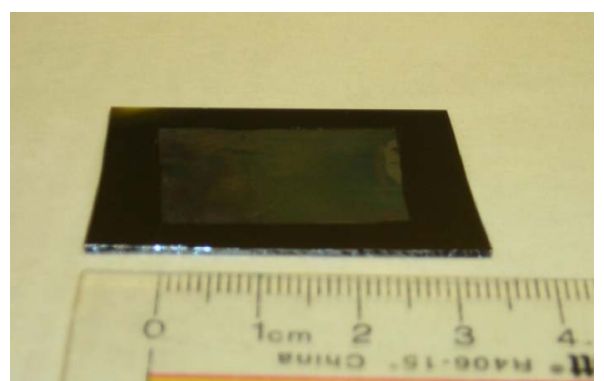

FIG. 1. (Color online) Image of a graphene film transferred to a $300 \mathrm{~nm}$ thick silicon oxide coated silicon wafer.

drogen at $650-700{ }^{\circ} \mathrm{C}$ in about 1 min growth time. Both the gases were flowed through the plasma. Typical flow rates of methane and hydrogen were 2.5 SCCM (SCCM denotes cubic centimeter per minute at STP) and 8 SCCM, respectively, with a total pressure of $90 \mathrm{mTorr}(0.12 \mathrm{~Pa})$. The rf plasma was operated at a frequency of $13.54 \mathrm{MHz}$ and at $250 \mathrm{~W}$ power (plasma density of about $40 \mathrm{~W} / \mathrm{cm}^{3}$ ). Without the plasma, under these conditions, energy dispersive X-ray spectroscopy (EDX) analysis showed no detectable film growth. However graphene films were produced on these substrates under similar flow conditions at $1000{ }^{\circ} \mathrm{C}$ via conventional CVD.

Although formation of graphene was detected with only methane, addition of hydrogen produced Raman signals with longer, narrower peaks. The improvement in the Raman signal in the presence of hydrogen can be explained as follows. An inductively coupled plasma produces a relatively high concentration of atomic hydrogen that is an important factor in the growth of the carbon nanosheets. ${ }^{18}$ It is known to etch amorphous carbon, $s p^{2}$ and $s p^{3}$ hybridized carbon at very different rates. ${ }^{19}$ Hence, it can selectively etch amorphous carbon defects that can serve as secondary nuclei for competing film growth. ${ }^{14}$ Hence, by eliminating or minimizing the competing growth, hydrogen promotes growth of higher quality of graphene.

Following growth, the graphene films were detached from the substrates by wet-etching the underlying $\mathrm{Ni}$ films and transferring the RPCVD grown film onto $300 \mathrm{~nm}$ thick $\mathrm{SiO}_{2}$ coated $\mathrm{Si}$ substrates. This was achieved by placing the substrates in a 0.25 molar ferric chloride solution that dissolved the Ni layer and freed the graphene film. In the case of the $\mathrm{Ni}$ foil, one should note that the graphene film grows on both the surfaces; hence there were two separate layers present in the solution. Before lifting the film, the etching solution was slowly replaced by de-ionized (DI) water to wash off the $\mathrm{Fe}$ and $\mathrm{Cl}$ contamination. Once transferred to the $\mathrm{SiO}_{2} / \mathrm{Si}$ substrates, the graphene films were further rinsed in DI water.

The variation in the graphene film thickness was visually discernable on the $300 \mathrm{~nm}$ thick oxide substrate by viewing it at almost grazing angles. It was determined that large area $\left(\sim 2.5 \times 2 \mathrm{~cm}^{2}\right)$ films (Fig. 1) were not entirely uniform: they were thicker near the middle, probably due to lower temperatures at the outer edge. The thickness variation was confirmed with Raman spectroscopy which provided a quick measure of the layer thickness and defects. As mentioned above, the (111) Ni crystallites on the polycrystalline surface were scattered on the Ni films and foil substrates, hence graphene domains grown were also distributed over the surface. On the other hand, the single crystals substrates had

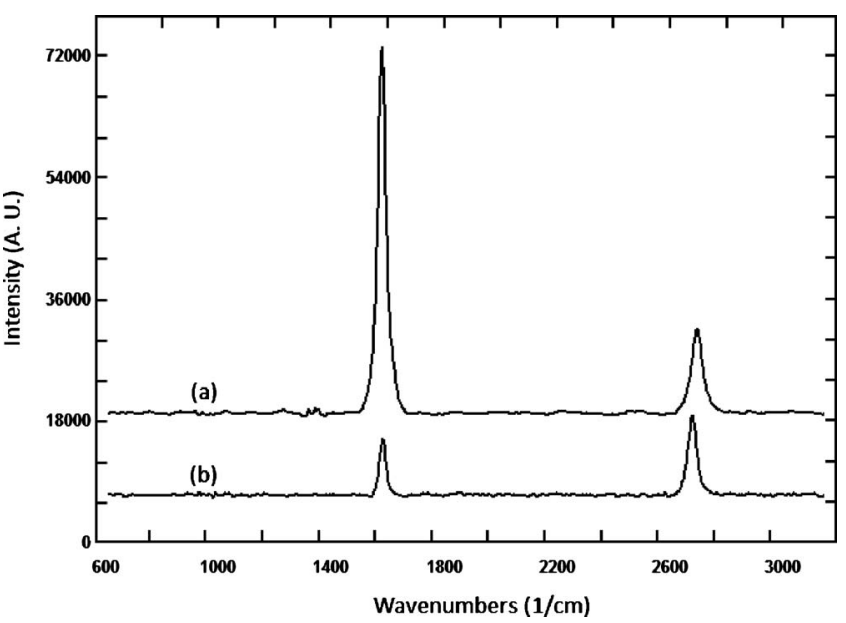

FIG. 2. Raman spectra of graphene on (a) nickel film and (b) silicon oxide coated silicon wafer.

uniform and continuous graphene film growth over about $80 \%$ of the surface, except near the corners. Raman spectra of the graphene film grown via RPCVD on a $300 \mathrm{~nm}$ thick $\mathrm{Ni}$ thin film and then transferred to a silicon/oxide silicon substrate are shown in Fig. 2. The sharp peaks are indicative of the crystallinity of the films and both plots show the two distinct peaks, one at about $1580 \mathrm{~cm}^{-1}$ ( $\mathrm{G}$ peak) and the other at about $2690 \mathrm{~cm}^{-1} 2 \mathrm{D}$ peak. The peak at around $1580 \mathrm{~cm}^{-1}$ is attributed to $s p^{2}$ phonon vibrations. ${ }^{20}$ The $2 \mathrm{D}$ peak is used to confirm presence of graphene and it originates from a double resonance process that links phonons to the electronic band structure. ${ }^{21}$ It can be seen in Fig. 2 that the ratio of $2 \mathrm{D}$ to $\mathrm{G}$ Raman peaks is larger for the transferred sample than for the film on the Ni substrate. The higher ratio implies that the film is closer to the near perfect exfoliated graphene. $^{20}$ The reason for this difference is that besides the graphene film, the Ni substrate contains other carbon species, mostly trapped at the grain boundaries of the polycrystalline substrate. Dissolving the Ni film will release these impurities which will be largely absent from the film transferred to the silicon substrate.

Graphene films grown on the $\mathrm{Ni}$ thin films were also transferred to glass microscope slides to measure optical transmission in the visible region (Fig. 3). Since the optical absorption of each graphene layer is about $2.3 \%$, we estimate this layer to be composed of an average of 7 layers. ${ }^{22}$ Transmission electron microscope (TEM) samples were prepared by lifting up small free floating graphene film fragments on copper TEM grids. FEI's Titan microscope (equipped with

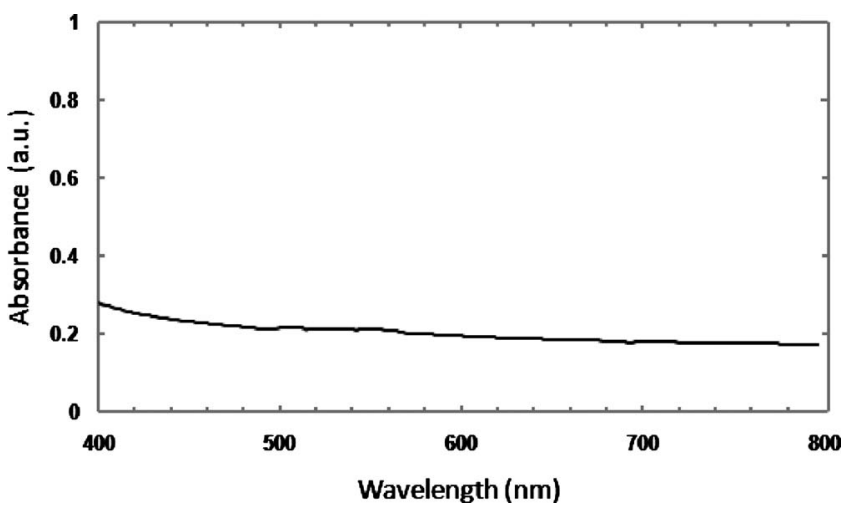

FIG. 3. Absorption spectrum of graphene on a glass slide. 


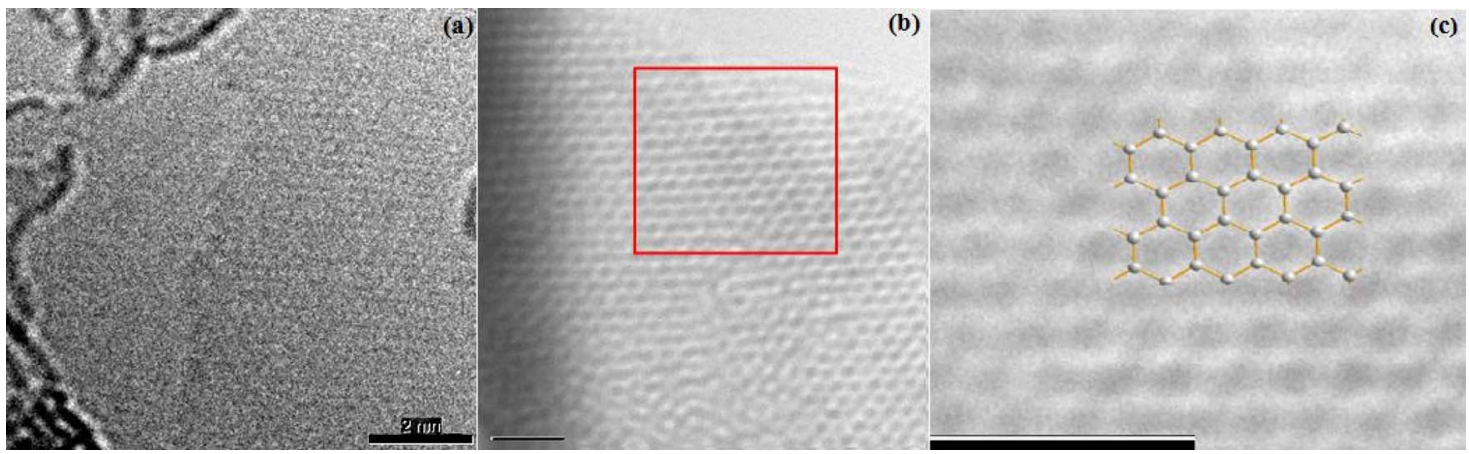

FIG. 4. (Color online) HREM images of graphene sheets taken on FEI Titan on the edge of a film. The structures near the edge of the image (a) are adsorbates (possibly of iron oxide). HREM image (c) of a single-layer graphene is enlarged region of (b) outlined by a red rectangle. The scale bars of images (b) and (c) are $1 \mathrm{~nm}$.

Cs-corrector) operated at $80 \mathrm{kV}$ was employed to view the graphene films at atomic resolution. Figure 4(a) shows high resolution electron microscope (HREM) image of single-, bi-, and multilayer graphene films, whereas Fig. 4(b) shows HREM image of a single-layer graphene region. Figure 4(c) shows enlarged region of Fig. 4(b) (marked by a red rectangle) and atomic sketch of graphene structure.

EDX analysis did show presence of iron oxide on some parts of the sample, most likely from the etching solution.

Electrical properties of the graphene deposited on $\mathrm{Ni}$ films were characterized by fabricating back-gated transistors on the $\mathrm{SiO}_{2}$ coated silicon substrates. Electron beam lithography was utilized to pattern the top electrodes, as shown in the inset of Fig. 5. By applying a gate voltage of $\pm 40 \mathrm{~V}$, conductance values were recorded. The plot shows a shift away from the Dirac zero point. The likely cause for this shift is presence of impurities, most likely residues from the Ni etching solution that was detected with the TEM. For this sample, we calculated an electron mobility of $3000 \mathrm{~cm}^{2} / \mathrm{V} \mathrm{s}$.

We have demonstrated that large area graphene films can be grown on nickel surfaces employing a remote plasma system in about one minute growth time. Remote plasma eliminates the orientation effect of the electrical field on the

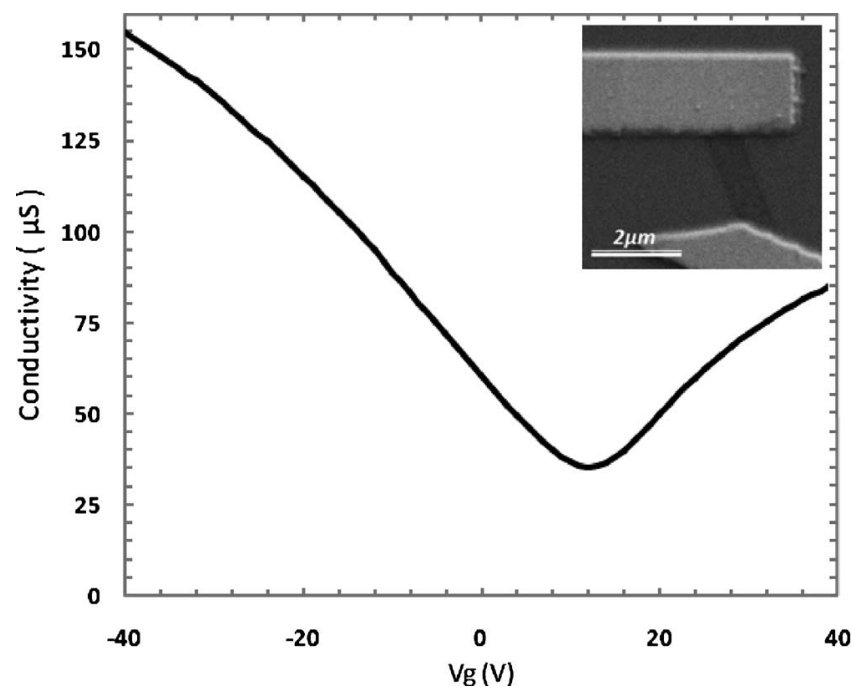

FIG. 5. Dependence of conductivity on gate voltage. The inset is a scanning electron micrograph of the device structure. grown film which plagues in situ plasma growth and allows film growth at lower temperatures compared to conventional CVD processes. Electrical and optical properties of the films indicate that they are similar to those produced by more conventional means.

This investigation was supported in part by the Office of Naval Research through Oregon Nanoscience and Microtechnologies Institute (ONAMI).

${ }^{1}$ Y. B. Zhang, Y. W. Tan, H. L. Stormer, and P. Kim, Nature (London) 438 , 201 (2005).

${ }^{2}$ T. Ohta, A. Bostwick, T. Seyller, and K. Horn, Science 313, 951 (2006).

${ }^{3}$ K. S. Novoselov, A. K. Geim, S. V. Morozov, D. Jiang, Y. Zhang, S. V. Dubonos, I. V. Grigorieva, and A. A. Firsov, Science 306, 666 (2004).

${ }^{4}$ H. Ueta, M. Saida, C. Nakai, Y. Yamada, M. Sasaki, and S. Yamamoto, Surf. Sci. 560, 183 (2004).

${ }^{5}$ N. Gall', E. Rut'kov, and A. Tontegode, Phys. Solid State 46, 371 (2004).

${ }^{6}$ P. W. Sutter, J. I. Flege, and E. A. Sutter, Nature Mater. 7, 406 (2008).

${ }^{7}$ S. Park and R. S. Ruoff, Nano Lett. 4, 217 (2009).

${ }^{8}$ C. Berger, Z. M. Song, X. B. Li, X. S. Wu, N. Brown, C. Naud, D. Mayo, T. B. Li, J. Hass, A. N. Marchenkov, E. H. Conrad, P. N. First, and W. A. de Heer, Science 312, 1191 (2006).

${ }^{9}$ H. H. Madden, J. Kuppers, and G. Ertl, J. Chem. Phys. 58, 3401 (1973).

${ }^{10}$ Y. Gamo, A. Nagashima, M. Wakabayashi, M. Terai, and C. Oshima, Surf. Sci. 374, 61 (1997).

${ }^{11}$ A. G. Starodubov, M. A. Medvetskii, A. M. Shikin, and V. K. Adamchuk, Phys. Solid State 46, 1340 (2004).

${ }^{12}$ Q. J. Yu, S. Lian, S. Siriponglert, H. Li, Y. P. Chen, and S.-S. Pei, Appl. Phys. Lett. 93, 113103 (2008)

${ }^{13}$ R. Sinclair, T. Itoh, and R. Chin, Microsc. Microanal. 8, 288 (2002).

${ }^{14}$ M. Zhu, J. Wang, B. C. Holloway, R. A. Outlaw, X. Zhao, K. Hou, V. Shutthanandan, and D. M. Manos, Carbon 45, 2229 (2007).

${ }^{15}$ A. Malesevic, R. Vitchev, K. Schouteden, A. Volodin, L. Zhang, G. Van Tendeloo, A. Vanhusel, and C. Van Haesendock, Nanotechnology 19, 305604 (2008).

${ }^{16}$ B. Chapman, Glow Discharge Processes (Wiley, New York, 1980), Chap. 5.

${ }^{17}$ S. K. Kwang, H. Ryua, and G. E. Jang, Diamond Relat. Mater. 2, 1717 (2003).

${ }^{18}$ J. J. Wang, M. Y. Zhu, R. A. Outlaw, X. Zhao, D. M. Manos, and B. C. Holloway, Carbon 42, 2867 (2004).

${ }^{19}$ M. Zhu, J. Wang, R. A. Outlaw, K. Hou, D. M. Manos, and B. C. Holloway, Diamond Relat. Mater. 16, 196 (2007).

${ }^{20}$ A. C. Ferrari, J. C. Meyer, V. Scardaci, C. Casiraghi, M. Lazzeri, F. Mauri, S. Piscanec, D. Jiang, K. S. Novoselov, S. Roth, and A. K. Geim, Phys Rev. Lett. 97, 187401 (2006).

${ }^{21}$ C. Thomsen and S. Reich, Phys. Rev. Lett. 85, 5214 (2000).

${ }^{22}$ R. R. Nair, P. Blake, A. N. Grigorenko, K. S. Novoselov, T. J. Booth, T. Stauber, N. M. R. Peres, and A. K. Geim, Science 320, 1308 (2008). 
Applied Physics Letters is copyrighted by the American Institute of Physics (AIP). Redistribution of journal material is subject to the AIP online journal license and/or AIP copyright. For more information, see http://ojps.aip.org/aplo/aplcr.jsp 